\title{
A IMPORTÂNCIA DO DESENHO NO CALCULO ESTRUTURAL PARA A ENGENHARIA CIVIL
}

\author{
$\underline{\text { Samuel de Souza Silva Buruaem; }}$; Ana Rita Sulz de Almeida Campos²; \\ 1. Bolsista PIBIC/CNPq, Graduando em Engenharia Civil, Universidade Estadual de Feira de \\ Santana, e-mail: samuelburuaem@ hotmail.com \\ 2. Orientadora, Departamento de Letras, Universidade Estadual de Feira de Santana, e-mail: sulz@uefs.br
}

PALAVRAS-CHAVE: Importância; Desenho; Calculo Estrutural.

\section{INTRODUÇÃO}

Construir significa antes de tudo planejar, é preciso um projeto para posteriormente uma execução. Toda construção necessita de uma estrutura suporte e é nesse aspecto que surge a importância de se conhecer os elementos estruturais. A função prioritária de uma estrutura em uma construção é garantir a forma espacial idealizada e segura por um determinado período de tempo. Essas estruturas ou sistemas estruturais podem ser entendidos como a disposição racional e inteligente de diversos elementos estruturais sendo estes elementos sólidos deformáveis com capacidade de receber e transmitir solicitações no geral. Sendo assim, o objetivo geral dessa pesquisa é estudar a importância do desenho no calculo de estrutura convencional; laje, viga e pilar.

Para Souza e Cunha (1998), na construção de uma edificação é necessário que o engenheiro civil tenha conhecimento técnico em desenho para proceder os seguintes passos do projeto estrutural: desenho da planta de cargas e locação dos elementos estruturais, planta de formas e detalhamento das armações ou ferragens. Os elementos estruturais devem estar presentes no projeto, de tal maneira que essa criação atenda todas as exigências do projeto estrutural. Aliado a isso deve se pensar também na forma mais apropriada para atender essas exigências com o menor custo possível, sempre com os níveis de segurança satisfatórios. Para concepção estrutural adequada é necessário levar em conta a finalidade do projeto arquitetônico, pois este determina o posicionamento das estruturas.

No tocante a importância do desenho no calculo estrutural, implica-se que para projetar um calculo de uma laje maciça, viga ou pilar, por exemplo, necessita-se que o projetista tenha conhecimento de desenho técnico e noções das normas técnicas para que o projeto venha a se tornar coerente nas fases de planejamento e montagem da edificação. Visto que, a importância do desenho no cotidiano de um engenheiro projetista é transmitir com exatidão todas as características do objeto que representa.

\section{METODOLOGIA}

Este trabalho se baseou em pesquisa bibliográfica, e apresenta os conceitos das etapas do calculo de estruturas e os conhecimentos necessários sobre o desenho no calculo estrutural para a engenharia civil, especialmente da estrutura convencional - conjunto de laje, viga, e pilar.

Observou-se a importância na representação dos elementos do desenho de formas, por exemplo, as formas de pilares, lajes e escadas no desenho de formas. Sendo assim, esse trabalho foi baseado nos conceitos das normas (NBR) dos elementos estruturais, e a importância o desenho técnico, que é a forma de expressão gráfica que tem por finalidade a representação da forma, dimensão e posição de objetos de acordo com as diferentes 
necessidades requeridas pelas diversas modalidades de engenharia e também arquitetura, pois a linguagem do desenho é universal da engenharia (BORTOLOTI, 2011, p.1).

\section{RESULTADOS/DISCUSSÃO}

Inicialmente é importante definir o que significa estrutura. Para Rebello (2001), "estrutura é tudo aquilo que sustenta tal qual o esqueleto humano. Está em tudo que nos rodeia, nas plantas, no ar e nas pessoas, nos objetos e nas ideias". Nas edificações a estrutura é o conjunto de elementos (lajes, vigas, pilares, etc.) que dela faz parte e tem a função de manter o edifício estável, imóvel, seguro durante a sua construção e utilização. A estrutura tem também a função de possibilitar as diferentes formas arquitetônicas e de criar espaços livres para a utilização das pessoas.

Construir significa antes de tudo planejar, é preciso um projeto para posteriormente uma execução. Toda construção necessita de uma estrutura suporte e é nesse aspecto que surge a importância de se conhecer os elementos estruturais. A função prioritária de uma estrutura em uma construção é garantir a forma espacial idealizada segura por um determinado período de tempo, essas estruturas ou os sistemas estruturais podem ser entendidos como a disposição racional e inteligente de diversos elementos estruturais sendo estes elementos sólidos deformáveis com capacidade de receber e transmitir solicitações no geral. Sendo assim, o objetivo geral dessa pesquisa é estudar a importância do desenho no calculo de estrutura convencional; laje, viga e pilar.

\section{Etapas do calculo estrutural}

Antes de dizer sobre os elementos estruturais, é importante definir alguns conceitos básicos sobre a geometria dos elementos, pois a geometria dos elementos estruturais é o que vai nos proporcionar a compreensão do comportamento estrutural. A classificação é feita a partir da geometria, a diferença está na ordem de grandeza das três dimensões principais do elemento (comprimento, altura e espessura).

Laje: As lajes são os elementos planos que se destinam a receber a maior parte das ações aplicadas numa construção, como de pessoas, móveis, pisos, paredes, e os mais variados tipos de carga que podem existir em função da finalidade arquitetônica do espaço físico que a laje faz parte, lajes maciças de concreto (Fig.1)

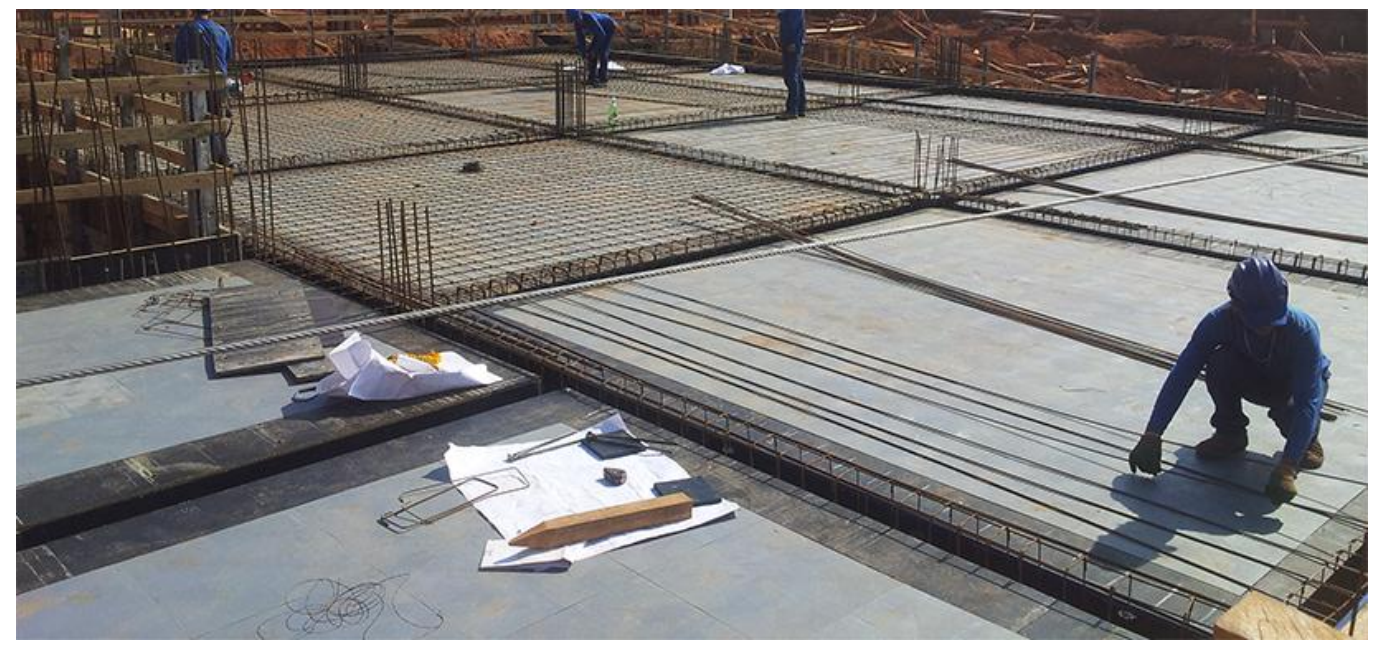

Figura 1 Laje Maciça em construção. Fonte: Planex-A fôrma da laje plana 
Vigas: Pela definição da NBR 6118/03 (item 14.4.1.1), vigas "são elementos lineares em que a flexão é preponderante". As vigas são classificadas como barras e são normalmente retas e horizontais, destinadas a receber ações das lajes, de outras vigas, de paredes de alvenaria, e eventualmente de pilares (Figura 2).

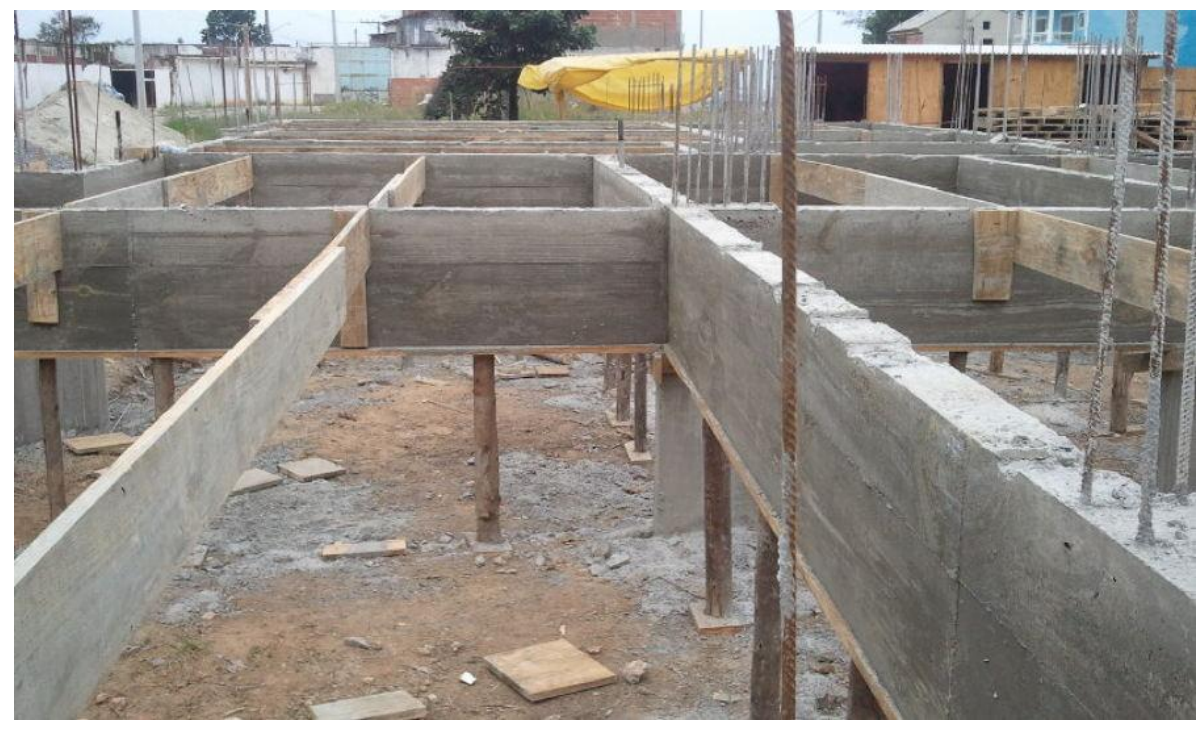

Figura 2: Imagem de uma montagem de uma viga.

Fonte: Em construção-Casa nova.

Pilares: São "elementos lineares de eixo reto, usualmente dispostos na vertical, em que as forças normais de compressão são preponderantes" (NBR 6118/03, item 14.4.1.2).São destinados a transmitir as ações às fundações, embora possam também transmitir para outros elementos de apoio. Este é o elemento mais importante nas estruturas, tanto pela capacidade de resistência quanto no aspecto da segurança. Também são de extrema importância para a estabilidade global dos edifícios

\section{Desenho no cálculo estrutural}

Para Souza e Cunha (1998) na construção de uma edificação é necessário que o engenheiro civil tenha conhecimento técnico para proceder no desenho os seguintes passos no projeto estrutural: desenho da planta de cargas e locação dos elementos estruturais , planta de formas e detalhamento das armações ou ferragens. Uma vez decidido à solução estrutural da edificação, deve-se registra lá em desenho que possa ser interpretada pelos carpinteiros que irão executar a forma, que conterá o concreto fresco (REBELLO; 2005 p.335), o desenho para a execução das formas deve ser feito de maneira a ter o perfeito conhecimento da forma e dimensão das peças, devendo conter vistas, cortes e detalhes. A escala mais utilizada é de 1:50, podendo ser também ser usado a escala 1:100 desde que a clareza não seja prejudicada.

\section{A Importância do Desenho nas etapas do Calculo Estrutural e as Normas técnicas utilizadas}

NBR 10647 (Abr/1989) - esta norma estabelece, dentre outras terminologias, a classificação do desenho segundo o seu aspecto geométrico. O desenho técnico pode ser dividido em duas grandes modalidades: Desenhos projetivos: abrange aqueles desenhos, cujo objetivo é a demonstração da forma e das medidas proporcionais dos objetos. É representada por meio de vistas ortográficas e perspectivas. Ex.: projetos de fabricação de máquinas e equipamentos; projetos e construção de edificações de vários tipos, envolvendo detalhes elétricos, 
arquitetônicos, estruturais, etc.; projetos para construção de rodovias, aterros, drenagem, barragens, açudes, etc.; projetos planialtimétricos e topográficos; desenvolvimento de produtos industriais; projetos paisagísticos; dentre outros.

Pode-se considerar o processo de um projeto de calculo estrutural como uma das mais importantes etapas para construção de edificações, pois nos últimos anos a complexidade dos projetos e as exigências nas qualidades das construções fizeram com que os engenheiros civis se qualificarem cada vez mais, principalmente nos quesitos de normas e segurança nas etapas do calculo estrutural.

\section{CONSIDERAÇÕES FINAIS}

Estudar a importância do desenho no calculo estrutural em uma construção é dizer as funcionalidades das plantas de formas, plantas de cargas e armações das ferragens de um sistema estrutural. A estrutura é a parte mais resistente de uma construção, há uma grande absorção e transmissão de esforços dentro deste sistema o que garante solidez e segurança para a construção. A combinação de elementos estruturais (laje, viga e pilar) da origem aos sistemas estruturais que é o conjunto formador da estrutura e que transmite os esforços ao solo, daí a necessidade de serem construídas com matérias não perfeitamente rígidas, ou seja, obedecendo as normas da NBR e os quesitos de seguranças da mesma.

Portanto com o crescimento tecnológico, na economia e principalmente na construção civil, o desenho no ramo estrutural é de extrema importância principalmente em questões de segurança e analise dos procedimentos para a construção de obras, sendo que o conhecimento em desenho aprimora a vida dos engenheiros.

\section{REFERÊNCIAS}

ASSOCIAÇÃO BRASILEIRA DE NORMAS TÉCNICAS. Projeto de estruturas de concreto - Procedimento - NBR 6118. Rio de Janeiro, ABNT, mar/2003, 221p.

ASSOCIAÇÃO BRASILEIRA DE NORMAS TÉCNICAS (1994). NBR 6492 Representação de projetos de arquitetura, Rio de Janeiro.

CORRÊA, R. M. ; NAVEIRO, R. M. Importância do ensino da integração dos projetos de arquitetura e estrutura de edifícios: fase de lançamento das estruturas, s/d., $5 \mathrm{p}$.

REBELLO, Y.C.P. A concepção estrutural e a arquitetura. S. Paulo, Zigurate Editora, 2001,271p.

SOUZA, Roberto; MEKBEKIAN, Geraldo. Qualidade na aquisição de materiais e execução de obras. São Paulo: Pini, 1996. 275p 